\title{
GRUPO E TRABALHO COLETIVO NA ESCOLA: TROCANDO OLHARES, MUDANDO PRÁTICAS'
}

\section{Laura Noemi Chaluh*}

RESUMO: O presente artigo trata do trabalho desenvolvido por um grupo de formação instituído em uma escola de ensino fundamental da Rede Municipal de Campinas-SP, no período de 2004 a 2005, cujo objetivo foi a redefinição do trabalho com as classes de alfabetização. Uma das inquietações do grupo foi a não-aprendizagem de alguns dos alunos das primeiras séries no tempo que a escola seriada estipula. Em função disso, as professoras promoveram uma mudança significativa ao assumir a responsabilidade pela aprendizagem de todos os alunos dessas séries que precisavam de "outros tempos". Enfatizo, neste texto, a potencialidade do trabalho conjunto dessas professoras quando decidiram mudar a prática do reforço já instituída na escola, prática solitária professoraaluno. A prática coletiva do reforço estabeleceu novas formas de organização que possibilitaram aos alunos vivenciar o trabalho com outras professoras, bem como proporcionar-lhes a possibilidade de trocar olhares sobre um mesmo aluno.

Palavras-chave: Formação; Trabalho Coletivo; Prática Pedagógica

\section{JOINT GROUP AND WORK IN SCHOOL: \\ EXCHANGING LOOKS, CHANGING PRACTICES}

ABSTRACT: The work developed by an educational group of an Elementary School in the Municipal Schools of Campinas (SP) during 2004-2005, aiming at restructuring the teaching of reading classes is reported. One of the group issues was the learning deficiency of some first-grade students in relation to the expectancy standard. Thus, the teachers furthered a deep change, responsible as they were for the development of all those who needed "some other time" to learn. These teachers' joint work potentialities are emphasized as they change the traditional reinforcement classes at school, a solitary teacher-student practice, contrasting to the collective reinforcement practice which established new forms of organization that enabled students to interact with different teachers, and created the opportunity for teachers to exchange varying points of view about one same student.

Keywords: Education; Joint Work; Pedagogical Practice

\footnotetext{
*Doutora em Educação pela Faculdade de Educação da Universidade de Campinas (UNICAMP); Integrante do Grupo de Estudos e Pesquisas em Educação Continuada (GEPEC) e Professora do Ensino Primário. Licenciada em Ciências da Educação. E-mail:chaluh@uol.com.br
} 
"O que humaniza o olho do homem é a humanidade do objeto." (Valdemir Miotello)

\section{PESQUISAR NA ESCOLA}

Estive inserida como pesquisadora em uma escola de ensino fundamental da Rede Municipal de Campinas, desde agosto de 2003 até dezembro de 2005. A questão que me inquietava era saber como seria a constituição do grupo dos professores na escola em um sistema em que, segundo a política pública de formação, havia um favorecimento do trabalho coletivo e dos espaços de formação dentro da escola. Assim, perguntei-me: quais os sentidos que assume a política pública de formação quando chega à escola?

Para entender o cotidiano da referida instituição, considerei a abordagem da escola a partir da concepção de Rockwell e Ezpeleta (1986), que observam a importância de olhar a realidade da escola como "positividade", no sentido do existente (p. 10). Essa concepção implica entrar na escola e olhar o que nela existe, vendo a escola em si mesma, considerando o que nela acontece, e aí estará a sua positividade. Para as autoras, a escola, mesmo fazendo parte de um movimento maior ( $\mathrm{da}$ história, de relações sociais, do sistema educacional), recebe em cada lugar uma versão única, surge "a necessidade de olhar com particular interesse o movimento social a partir de situações e dos sujeitos que realizam anonimamente a história" (ROCKWELL E EZPELETA, 1986, p. 11).

As teorias tradicionais têm trabalhado a partir de uma história documentada, que mostra a escola como instituição homogênea, no sentido que ela se repete em todos os lugares e que nela se reproduzem os mesmos sistemas de valores. Segundo Rockwell e Ezpeleta (1986, p. 13), coexiste, "contudo, com esta história e existência documentada, outra história e existência não documentada, através da qual a escola toma forma material, ganha vida".

De todos os caminhos percorridos nessa escola, opto, neste texto, por narrar a constituição e o desenvolvimento de um dos grupos instituídos nela, o Grupo de Reflexão sobre Letramento e Alfabetização (GA). Pretendo dar visibilidade ao trabalho desenvolvido por esse grupo, apontando as ações pedagógicas promovidas ao longo dos anos 2004 e 
2005, destacando uma mudança muito signficativa em relação à concepção da "prática do reforço" já instituída na escola.

Ao dar visibilidade ao trabalho desenvolvido por esse grupo, resgato a idéia de construção social da escola (ROCKWELL; EZPELETA, 1986), realizada anonimamente por cada um dos sujeitos que fazem a história da escola cotidianamente. A singularidade de um trabalho coletivo desenvolvido em uma escola evidencia as ações dos sujeitos anônimos, ou sujeito ordinários, no dizer de Certeau (2002), as professoras que fazem/ constroem a escola pública no dia-a-dia.

\section{A FORMAC̦ÃO DAS PROFESSORAS: UM OLHAR A PARTIR DOS DISCURSOS DA POLÍTICA}

Considero importante apontar algumas das idéias centrais que sustentaram a proposta educativa da Secretaria Municipal de Educação de Campinas (SME), no período de 2001 a 2004. Em especial, destaco os discursos dessa gestão em relação à questão da formação das professoras dessa rede.

Da leitura da documentação elaborada por essa Secretaria, depreende-se uma valorização das professoras como sujeitos que têm nas mãos possibilidades para promover mudanças. No primeiro boletim ${ }^{2}$ (SME, 2001a), apareceram oito princípios que embasavam algumas ações que se pretendiam realizar nessa gestão, dos quais resgato: "respeito aos saberes dos profissionais da educação, para que não se perca o que já foi construído", "compreensão do profissional como alguém que está em contínuo aprendizado, sendo, portanto, capaz de agir". Em outro boletim, considerava-se que "participar de Grupos de Formação é um direito dos profissionais de Educação e um compromisso político-pedagógico desta Secretaria” (SME, 2001b). Importante ressaltar que, segundo a Secretaria, não basta que os profissionais só divulguem práticas e promovam estudos, considerando que é fundamental que a escola olhe para esses grupos "como necessários ao seu trabalho pedagógico e que os grupos propiciem um retorno das atividades desenvolvidas à comunidade escolar". Isso tem a ver com as dificuldades que existiam em algumas escolas quando alguns docentes participavam dos Grupos de Formação (GF’s), mas isso não era levado para a própria comunidade escolar que desconhecia o trabalho desenvolvido. Nesse sentido, não se potencializavam os benefícios advin-dos da reflexão promovida nos GF's, esvaziando-se o sentido da existência dos mesmos. 
Uma das propostas da Secretaria para inverter essa situação foi que os Grupos de Formação fossem definidos e organizados a partir das demandas que surgissem dentro do Projeto Pedagógico de cada uma das escolas. Entre as propostas da Secretaria para a constituição dos grupos estava a opção de construí-los não só com base nas disciplinas, mas também por temáticas: "se várias escolas de uma região entenderem ser necessária a discussão de um tema, como a violência, por exemplo, a região poderá ter um grupo de formação multidisciplinar para trabalhar esta temática” (SME, 2001b).

Ainda com a questão da formação, Geraldi (2004, p. 50), então secretária de educação, apontava a necessidade de considerar uma formação contínua dos educadores que resgatasse "o sentido da autoria dos educadores e educadoras, da produção coletiva do projeto pedagógico da escola, a partir de novos modos de organização do trabalho pedagógico e de sua avaliação".

E qual o sentido da autoria? Para compreender o sentido que assume pensar na autoria dos educadores retomo a Kramer (2003, p. 83): "ser autor significa dizer a própria palavra, cunhar nela sua marca pessoal e marcar-se a si e aos outros pela palavra dita, gritada, sonhada, grafada [...] Ser autor significa produzir com e para o outro".

A questão da autoria também foi considerada por Collares, Moysés e Geraldi (2001, p. 212): “assumir o lugar de onde se fala é constituir-se como sujeito, múltiplo, polifônico e único em sua própria organização narrativa". Nesse sentido, os autores questionam os programas de formação continuada de professores que atendem aos planos de governo e que desconsideram as políticas assumidas pelos profis-sionais do ensino. Assim, nesses processos de formação continuada, qual o lugar que ocupam os saberes que nascem nos acontecimentos da sala de aula?

Ao pensar na autoria dos professores, temos de analisar, necessariamente, a relação que temos estabelecido com o conhecimento. Onde fica "guardado" tudo o que temos produzido, desenvolvido como professores, com nossos alunos e alunas, com nossos colegas? O reconhecimento da autoria passa, necessariamente, pelo resgate tanto das experiências quanto dos saberes produzidos na sala de aula e nos encontros com os outros professores, para que eles deixem de estar ocultos, para que eles tenham vida, mostrando, assim, toda a sua potencialidade.

Acredito que Davini (1999), quando problematiza a questão do docente como profissional, traz para a discussão a autoria, ao apontar que profissional é aquele que pode dar conta de suas decisões e que vai 
produzindo conhecimento nessas decisões. Nesse sentido, e tendo como pano de fundo a profissionalização dos docentes, a autora considera que os professores aprendem com base na própria prática, sistematizando o conhecimento. Ao pensarmos na profissionalização dos docentes, temos de compreender a importância que assume a construção de conhecimentos, já que desconsiderar essa construção implica esvaziar o sentido outorgado ao termo profissionalização (DAVINI, 1999).

As questões apontadas em relação à formação dos professores e à autoria são importantes para compreender uma decisão tomada pela SME a partir do ano de 2004, ao possibilitar a constituição de um Grupo de Trabalho sobre Alfabetização nas escolas de Ensino Fundamental dessa rede. As instituições podiam optar pela conformação desse Grupo dentro delas. Segundo consta no documento:

Professores de $1^{\mathrm{a}}, 2^{\mathrm{a}}$ e $5^{\mathrm{a}}$ séries do ensino fundamental das escolas municipais de Campinas vão receber duas horas aulas a mais para fazer um trabalho de formação e ajudar a reduzir o número de retenções de alunos com dificuldade de aprendizado (SME, 2004).

Um fato importante dessa possibilidade oferecida pela SME é pensar que a constituição desse Grupo de Trabalho em cada uma das escolas da rede evidenciaria as ações desenvolvidas pelos diferentes grupos a partir da singularidade de cada uma das escolas: quais as ações desenvolvidas nesses grupos e quais as relações que as professoras poderiam tecer nesse espaçotempo de formação?

A Secretaria aposta e acredita que os sujeitos que estão na escola podem ser responsavéis pelo encaminhamento das ações, dos percursos singulares com base no que, no grupo, aparece como inquietação, especificamente em relação à alfabetização. Muitas das escolas decidiram aceitar a proposta. Tive a possibilidade de participar e acompanhar a constituição de um desses grupos na Escola Padre Franciso Silva. Nela, as professoras das primeiras e segundas séries decidiram, juntamente com a orientadora pedagógica, aceitar a proposta da Secretaria.

Assim, neste trabalho, pretendo dizer da autoria grafada, dita, gritada, produzida no e pelo grupo de trabalho constituído na escola mencionada. 


\section{A ESCOLA: O DESAFIO DE CONSTITUIR O GRUPO DE TRABALHO}

A escola Padre Francisco Silva está instalada no bairro Jardim Londres, na zona nordeste do município de Campinas, SP. É uma escola pequena para os padrões da rede e acolhe perto de 500 crianças, divididas em 15 turmas, ocupando as cinco salas nos três períodos de funcionamento: manhã, intermediário, vespertino. No período noturno, funcionam classes de ensino de jovens e adultos.

O Grupo de Trabalho possibilitado pela SME, iniciado em março de 2004, foi chamado de Grupo de Reflexão sobre Letramento e Alfabetização. A responsabilidade pela coordenação dos encontros foi assumida por todas as participantes. Importa destacar que a diretora e eu, a pesquisadora, também participamos desse encontro. Existia um caderno coletivo de registro, no qual eram feitas as anotações do encontro por um dos participantes, segundo um rodízio já estabelecido. Trago algumas considerações registradas nesse caderno, já que dão conta das expectativas das integrantes do grupo em relação ao trabalho que iria ser realizado:

A partir da necessidade observada no grupo de professoras de $1^{\mathrm{a}}$ e $2^{\mathrm{a}}$ série com relação aos processos de aquisição da leitura e da escrita, decidimos organizar um grupo de estudos, reflexão e prática. [...]

A expectativa do grupo é a redefinição das diretrizes norteadoras do trabalho com as classes de alfabetização à medida que tomamos consciência de nossa própria prática.

Este é o conjunto de expectativas do grupo para uma proposta que estará sendo construída a cada encontro. (Caderno n. 1 do GA)

A constituição do Grupo de Reflexão sobre Letramento e Alfabetização tinha como objetivo ser um espaço de reflexão, de troca de experiências e de ampliação dos conhecimentos relativos ao processo de aquisição da escrita pelos alunos. A questão principal era poder identificar que concepções sustentavam as práticas pedagógicas e a organização do trabalho pedagógico dessas professoras na sala de aula e, com base nisso, pensar em um trabalho conjunto com as classes de alfabetização que permitisse levar em consideração o processo singular de aprendizagem de cada um dos alunos dessas séries. Isso porque uma das questões centrais abordadas pelas professoras era o desafio de trabalhar com a heterogeneidade na sala de aula, em especial com a questão da aprendizagem da escrita e da leitura dos alunos. A seguir, explicito algumas das ações desenvolvidas pelo grupo no período de 2004 e 2005. 
Uma das primeiras atividades desenvolvidas nesse encontro, a partir de 2004, foi a socialização do curso "Letramento e Alfabetização", oferecido pela SME e divulgado por uma das professoras do grupo que participava daquele curso, a profa. Ítala, que, na época, era professora da primeira série e trouxe várias contribuições que nos levaram a discutir sobre como fazer as melhores intervenções com os alunos para promover a aprendizagem da escrita. A professora socializou alguns dos textos oferecidos a ela no curso. Tais textos eram lidos no grupo e, com base neles, iniciavam-se as discussões.

A partir dos textos socializados pela professora Ítala, das inquietações levantadas no grupo e das experiências na sala de aula socializadas pelas professoras, outras interrogações começaram a ser discutidas no grupo: considerar ou não a cultura da criança? Há que se mostrar a norma culta na escola? Como é que a escola favorece o letramento? Quais as intervenções didáticas adequadas às diferentes concepções? A criança escreve, pode produzir texto sem estar alfabetizada? Quando isso acontece? É possível estar alfabetizado e não saber produzir textos? É possível estar alfabetizado e não ser letrado? Todos os alfabetizados conseguem fazer textos? Como oferecer mais oportunidades de letramento? Como criar um ambiente alfabetizador na sala de aula com a mediação da professora? Como avaliar o progresso de cada aluno e como definir as estratégias de intervenção para cada grupo, de acordo com os níveis de aprendizagem? Essas foram algumas das inquietações que começaram a se mostrar no grupo.

As questões que mais preocupavam as professoras eram que tipos de intervenções teriam que realizar com cada um dos seus alunos para favorecer a aprendizagem deles e que seriam diferentes em função do nível $^{4}$ (pré-silábico, silábico, silábico-alfabético) em que esses alunos e alunas estavam. Um dos aspectos que a professora Ítala resgatou do curso que realizava foi justamente a possibilidade de conhecer estratégias e tipos de intervenções, levando em consideração os níveis de aquisição da escrita dos alunos. Nesse sentido, uma das atividades desenvolvidas no grupo foi a socialização, por parte das professoras, das produções dos seus alunos, na tentativa de fazer uma análise de suas produções: nível de escrita, estratégias que favoreceriam a aprendizagem desses alunos, modalidade de trabalho adequada (individual, dupla, pequeno grupo), sugestão de propostas de atividades específicas.

Também tivemos a oportunidade de assistir a uma série de vídeos que refletiam a prática das professoras na sala de aula, mostrando 
estratégias que possibilitavam o processo de aprendizagem das crianças em relação à escrita a partir de um referencial teórico de como é que as crianças aprendem, tendo como fundamentação a psicogênese da leitura e da escrita, estudada por Emília Ferreiro. Fizemos uma seleção de alguns deles por considerá-los importantes nas nossas discussões e decidimos assistir juntas para, depois, discuti-los.

Destaco que, tanto a leitura e a discussão dos textos quanto os vídeos mostraram-se estratégias importantes que mediaram a relação entre a prática e a teoria, possibilitando o conhecimento de outras formas de promover a alfabetização.

Outra atividade promovida em 2004 foi a socialização de um artigo escrito por uma das professoras ${ }^{5}$ do grupo, fundamentado na sua dissertação de mestrado, que tinha como tema a ansiedade nas crianças. As discussões desse artigo permitiram refletir sobre as atitudes familiares que desencadeiam a ansiedade nas crianças. Foram explicitadas algumas categorias que indicavam determinado "modelo de pais" e deixando em evidência que cada um desses modelos poderia gerar determinados sentimentos nos filhos, explicitando que o sentimento de desamparo é que leva à alta ansiedade.

Foi apresentada, também, a dissertação de mestrado da diretora ${ }^{6}$ da escola sobre leitura e escrita. Essa produção discutia duas propostas de educação da década de 1990 atreladas à questão do ensino da escrita: a proposta positivista (de reprodução) e a proposta interacionista. A socialização desse trabalho tinha como pretensão discutir as propostas metodológicas que orientavam as práticas pedagógicas dessas duas perspectivas. A partir das questões levantadas nesse trabalho, o grupo começou a refletir sobre que tipo de leitor e escritor a escola estava formando. Foi possível compreender que, quando a escola trabalha com o treino e com a reprodução, está submetendo a criança à ordem, à norma, o que implica pensar na escrita como uma habilidade motora. Ao contrário, quando a escola respeita a escrita das crianças, permite que elas pensem sobre a mesma. As discussões levantadas com base nesse trabalho refletiram a importância de pensar na escrita e na sua intencionalidade: a escrita sempre é dirigida a alguém, tem um interlocutor (KRAMER, 2003; SMOLKA, 2003). Isso implicou, mais uma vez, refletir sobre a função social da escrita na escola.

Durante o ano de 2004, no GA, surgiu a necessidade de aprofundar o conhecimento de alguns conceitos sobre número, sistema de numeração decimal, trabalho com agrupamentos em diferentes bases. Em 
minha formação como professora, tinha tido um aprendizado importante em relação à Matemática. Em função disso, propus ao grupo fazer alguns trabalhos com material concreto para que, posteriormente, as professoras pudessem trabalhar essas questões com as crianças. Também trabalhamos alguns aspectos teóricos que embasavam essas atividades. $\mathrm{O}$ trabalho, no começo, foi planejado para dois encontros e, posteriormente, foi ampliado, quando fiquei responsável por coordenar outros encontros a partir da leitura de dois volumes dos textos ${ }^{7}$ Atividades Matemáticas para primeira e segunda séries. A leitura desses textos tinha como finalidade aprofundar o conhecimento sobre os conteúdos e os objetivos de Matemática para essas séries, tentando conhecer outras possibilidades do trabalho com os alunos.

Em 2005, além de dar continuidade a algumas das propostas desenvolvidas no ano anterior, houve a possibilidade de socializar e analisar atividades desenvolvidas pelas professoras com os alunos nas salas de aula.

Em relação à análise de atividades desenvolvidas pelas professoras na sala de aula, uma das professoras da segunda série, Cidinha, socializou a atividade que propus para seu grupo de alunos da escola após a apresentação de um circo, que contou com a presença de dois palhaços. A professora levou para a discussão o trabalho desenvolvido com gêneros textuais a partir do cartaz colocado na escola e que anunciava a presença dos palhaços. Sua proposta foi a produção de um cartaz. Esse encontro trouxe para a discussão, mais uma vez, a questão da função social da escrita. Pensar na escola e na sala de aula como um espaço que ofereça aos alunos a possibilidade de "aprender a falar e a escrever" implica lembrar a importância disso para organizar o nosso discurso (BAKHTIN, 2003), possibilitando a organização de nosso pensamento. Nesse sentido, foi importante retomar a questão de considerar quais os elementos que, em parte, determinam o tipo de enunciados que os alunos vão construir: quais as condições, qual a situação, para quem vão escrever, para que vão escrever. Essa questão foi fundamental para perceber que os enunciados são construídos a partir de uma situação, de um interlocutor, e que, para isso, é preciso, na escola, fugir do "fazer de conta que se escreve para alguém”, quando se cria uma ilusão na qual os alunos não só têm que imaginar o seu interlocutor, mas também a situação na qual vão ter que criar os discursos. Sabendo da complexidade que é entrar no "jogo do faz de conta", importa resgatar a idéia de que alunos, alunas e professoras entrem no jogo da situação concreta de diálogo, na corrente da linguagem, tal como aponta Kramer (2003). Entrar no "jogo do faz de conta" implica elaborar um cartaz sem que o produto dessa atividade 
torne-se efetivamente um cartaz. Assim, a partir das discussões, percebeuse a necessidade de criar condições para promover trabalhos com gêneros de textos que permitam a alunos e professores entrar no jogo da escrita, no jogo da produção, no jogo da comunicação.

Penso que a possibilidade de refletir sobre o próprio processo de ensino, como no caso referido, implica considerar a ação pedagógica como objeto de análise e intervenção. Como aponta Davini (2001), a reflexão sobre a prática no contexto específico e o desenvolvimento de alternativas para a ação na escola e na aula possibilitam a constituição de um espaço que favorece a construção coletiva do ensino. Segundo a mesma autora:

existen innumerables situaciones de la vida escolar y del aula que podrían ser utilizadas como estudios de casos em la formación de grado o en el perfeccionamento y serían vinculantes de la reflexión sobre la práctica, la experiencia de los sujetos y el aporte de conocimientos especializados (2001, p. 136).

Aponto as considerações de Zeichner (2000), que foca a reflexão docente numa perspectiva crítica, considerando o docente como um profissional autônomo que reflete criticamente sobre a prática cotidiana para compreender tanto as características singulares dos diferentes processos de ensino-aprendizagem, quanto o contexto em que o ensino é oferecido, de modo que a sua atuação reflexiva facilite o desenvolvimento autônomo e emancipador dos que dele participam.

O trabalho desenvolvido nesse grupo reflete as considerações colocadas por Gimeno Sacristán (1988) em relação à importância da formação na escola. $\mathrm{O}$ autor considera que os momentos de formação na escola são decisivos para relacionar a teoria com a prática, para refletir sobre a ação, porque é nesse espaço que os problemas assumem dimensões reais e no qual aparece o autêntico sentido, porque surgem os contrastes entre as idéias e as práticas.

\section{A PRÁTICA DO REFORC̣O: PROMOVENDO UMA MUDANC̣A}

No ano de 2005, um episódio muito significativo aconteceu em relação ao Trabaho Docente Individual (TDI). O TDI era um espaço já instituído nas escolas da Prefeitura de Campinas destinado "ao atendimento de dúvidas de alunos, aulas de reforço e a aulas de recuperação paralela, atendimento a pais de alunos e outras atividades definidas com a 
Equipe Escolar" (PREFEITURA MUNICIPAL DE CAMPINAS, 2003). As crianças que, segundo as professoras, precisavam de outros tempos para aprender, além do da sala de aula, tinham a possibilidade de estar com a sua professora fora do horário escolar para ter outras experiências de aprendizagem.

Trago as considerações apontadas sobre o TDI porque, nas primeiras reuniões do GA do ano de 2005, as professoras das primeiras séries comentaram uma experiência que vivenciaram no final de 2004, quando tiveram que compartilhar a mesma sala (a escola é pequena) no momento de dar "reforço" para seus alunos. A partir dessa experiência conjunta, as duas professoras relataram a importância de considerar a possibilidade de efetivar alguma mudança em relação a como vinha sendo desenvolvido o TDI na escola.

Apareceu, assim, um desafio para o grupo. A situação narrada pelas professoras das primeiras séries e a leitura e a socialização, por parte de uma das professoras da primeira série, do livro de Weisz e Sanches $O$ diálogo entre o ensino e a aprendizagem, no qual explicitam-se experiências conjuntas entre professores na escola, mobilizaram a discussão do grupo sobre pensar em outras alternativas para esse espaço de TDI.

Em função disso, foi discutida a importância de resgatar o trabalho conjunto das professoras no espaçotempo destinado ao "reforço", que deixou de ser uma prática solitária professora-aluno e passou a ser um trabalho conjunto das professoras com os alunos, na expectativa de se estabelecerem novas formas de organização que possibilitassem aos alunos não só vivenciar o trabalho com outras professoras, mas também proporcionar a elas a possibilidade de "troca de olhares" sobre uma mesma criança. O TDI mudou a sua organização e passou a se chamar Grupo de Apoio (GAP), ganhando outra configuração.

Algumas das considerações apontadas pelas professoras valorizavam o que um outro - uma colega - poderia olhar e como poderia contribuir em relação à aprendizagem de seus próprios alunos. Quais seriam as estratégias promovidas pela colega ao ser colocada em situações semelhantes às que ela vivencia? Qual seria a atitude dos alunos quando colocados para realizar uma atividade com outra professora?

Nos encontros no GA, as professoras remetiam-se ao Grupo de Apoio, apontando que, nesse espaçotempo, era muito importante o "olhar das outras colegas", tanto para enriquecer o trabalho delas mesmas quanto para favorecer a aprendizagem dos alunos. Nesse sentido, trago Bakhtin (2003), que, ao considerar a alteridade, o encontro com o outro e 
a exotopia, desdobramento de olhares a partir de um lugar exterior, traz importantes contribuições para pensarmos nas relações que estabelecemos não só com os nossos alunos e alunas na sala de aula, como, no caso, pensarmos nos encontros dessas quatro professoras que vivenciaram a possibilidade de compartilhar o mesmo espaço, a sala de aula, com alunos e alunas de diferentes professoras.

Qual a importância desse olhar, do olhar da colega? Qual a importância do olhar da colega para pensar na própira formação, para repensar a própria prática? Por que trazer essa questão? A partir de uma perspectiva bakhtiniana e sobre o excedente de visão, Geraldi (2003) nos diz que estamos expostos e quem nos vê o faz sempre com o "fundo" da paisagem em que estamos e a pessoa que nos vê tem uma experiência de nós que nós mesmos não temos, mas que podemos ter a respeito dele. "Este 'acontecimento' nos mostra a nossa incompletude e constitui o Outro como o único lugar possível de uma completude sempre impossível" (p. 44). Assim, a partir dessa questão, Geraldi (2003) nos leva à idéia dos próprios limites, da necessidade do outro para nos complementar e da idéia do inacabado que encontramos em Paulo Freire (2001, p. 153): "seria impossível saber-se inacabado e não se abrir ao mundo e aos outros à procura de explicação, de respostas a múltiplas perguntas". O encontro das professoras e o olhar de colegas permitiram outra dimensão das próprias práticas.

O Grupo de Apoio iniciou suas atividades nos primeiros meses do ano letivo de 2005. Sobre a organização do trabalho pedagógico dentro desse grupo, primeiro foram consideradas as dificuldades manifestadas pelas crianças que seriam atendidas nesses encontros e, em função disso, as professoras definiram com quais eixos cada uma delas iria trabalhar. A organização espacial da sala de aula no Grupo de Apoio dá conta de uma sala organizada por cantos de trabalho e cada professora ficou responsável por desenvolver atividades específicas com o grupo de alunos com os quais estaria. Trago a idéia de canto de trabalho porque ele tem como suposto que, em cada espaço da sala, está-se desenvolvendo uma atividade, oferecendo a possibilidade de haver, simultaneamente, ações diferenciadas acontecendo no mesmo espaço, tendo a possibilidade de as crianças fazerem diferentes propostas de atividades no mesmo dia, se necessário.

Entre as ações desenvolvidas pelo Grupo de Apoio, importa destacar: o trabalho conjunto das professoras no momento do planejamento (considerando as especificidades e necessidades de cada uma das crianças); a busca de material didático específico para o grupo de alunos 
que iriam atender nesses encontros; o rodízio dos alunos ao realizarem as atividades. A idéia era estar juntas no mesmo espaçotempo, cada uma das professoras sendo responsável por um grupo de alunos; os eixos considerados para o trabalho: leitura, interpretação de textos, produção de textos, etc.

As professoras decidiram que, no primeiro trimestre de 2005, o Grupo de Apoio organizaria atividades para os alunos das segundas séries, no segundo trimestre, atenderia aos alunos das primeiras séries e, no terceiro trimestre, seria avaliado o espaço e haveria a definição de quais seriam os alunos que participariam (foi decidido que seriam alunos tanto de primeira quanto de segunda série). Se o Grupo de Apoio focou, nos dois primeiros trimestres, a aprendizagem da leitura e da escrita, no último trimestre foram incluídas também atividades de matemática.

O trabalho desenvolvido no GAP pelas quatro professoras era discutido no espaço do GA. Entre as questões discutidas resgato: os saberes que as professoras construíram em relação aos alunos que elas acompanhavam; a problematização da importância de registrar o processo de aprendizagem dos alunos; as mudanças nas ações planejadas para cada pequeno grupo e cada aluno, em particular, em função dos acontecimentos que surgiam nos encontros do GAP; a explicitação das limitações dadas pela sala de aula e por sua configuração; a importância de aprender a administrar os conflitos que surgiram entre as professoras, já que levar à prática ações em forma conjunta implicava tomar decisões que nem sempre eram definidas por consenso, deixando em evidência que o trabalho em grupo implicava a possibilidade de mostrar as diferenças; as condições materiais da escola para facilitar (ou não) o trabalho proposto pelas professoras.

A constituição do GAP foi uma alternativa que o GA procurou, de modo a oportunizar outras vivências a algumas crianças em relação à sua aprendizagem. Segundo os relatos das professoras, um aluno repetente da segunda série que participava do GAP não só começou a chegar arrumado e perfumado a esses encontros, como começou a ter alguns avanços na sua aprendizagem e as professoras apontavam aspectos positivos em relação à sua "auto-estima". Começavam a aparecer algumas pistas que me permitiam fazer algumas interpretações. Quando Ginzburg (1989), a partir do paradigma indiciário, traz as noções de pistas, sinais e indícios, aponta que os mesmos são detalhes que, no acontecimento, podem-se apresentar aparentemente como secundários e irrelevantes, mas que são fundamentais para compreender determinada realidade. $\mathrm{O}$ fato de 
esse aluno começar a chegar no GA arrumado e perfumado fez-me refletir sobre quais as implicações que esse novo espaço constituído pelas professoras estava promovendo nos alunos e quais as diferenças com o espaço da sala de aula configurada nos moldes conhecidos. Por outro lado, a professora daquele aluno comentou que, na sala de aula com 35 alunos, ela não tinha percebido nenhuma mudança, pois ele não fazia as atividades, "não produzia".

$\mathrm{O}$ que faz a diferença no trabalho em um pequeno grupo tanto para os alunos quanto para as professoras? Por que esse aluno "não se sente confortável no espaço da sala de aula" e que restrições tem a sala de aula do jeito que é? Considero que o acontecimento narrado pela professora mostra as limitações da escola na forma como se apresenta hoje.

A constituição do GAP também foi considerada e registrada no Projeto Político Pedagógico (PPP) do ano de 2005 da escola. Nele, enfatizam-se as dificuldades apontadas pelos educadores da escola para trabalhar com a heterogeneidade da sala de aula. Nesse sentido, uma preocupação da escola foi a busca por alternativas e estratégias diferenciadas em momentos diferentes para as crianças que precisavam de outros tempos além do da sala de aula. Gostaria de resgatar aqui a importância dada no PPP da escola ao "olhar" que uma outra professora poderia ter sobre o mesmo aluno:

professores das séries iniciais (1as. e 2as. séries) elaboraram uma proposta de vivenciar novas formas de organização de atendimento possibilitando aos alunos experimentar o trabalho de outras professoras e às professoras a "troca de olhares" sobre uma mesma criança. (ESCOLA PADRE FRANCISCO SILVA, 2005, p. 23)

Trago algumas falas das professoras ${ }^{8}$ que constituíram o GAP para encontrar pistas sobre as contribuições que esse espaço teve para elas:

Eu acho que o que é importante é a gente estar as quatro no mesmo ambiente para ter aquele olhar diferenciado, por exemplo, eu não conheço o trabalho com o Paulo', eu não conheço como que é trabalhar com o Paulo, mas eu, estando de fora, sendo uma professora diferente do grupo, vendo como a outra professora está trabalhando o Paulo, como ele reage, eu posso talvez ter um outro tipo de intervenção. Então essa é uma possibilidade. Eu acho que é isso aí, mais ou menos. Para mim, pessoalmente, o mais importante é essa coisa da gente ampliar o repertório das ações, de como uma trabalha, de como a outra trabalha. (Professora da segunda série, Mônica ${ }^{9}$ )

Eu garimpo tudo o que acontece, sabe, eu aproveito muito bem as idéias dos outros. [...] Porque do mesmo jeito que eu acredito em algumas coisas que eu 
continuo fazendo, eu também vejo outras possibilidades e eu experimento. Se eu vejo um material diferente. [...] Eu estou colaborando muito com essa parte do Grupo de Apoio aí com um material que eu já organizei, trabalhei o ano retrasado, mas também eu estou bem aproveitando o material que elas coletam. Quer dizer, eu acho que a troca está sendo muito produtiva,está sendo interessante para todo mundo. (Professora da segunda série, Cidinha)

É muito legal para você ver como o outro colega trabalha, como é que ele intervém. Para você analisar sua própria intervenção, porque às vezes você vê uma atitude no colega que te choca, mas que, de repente, você se pega fazendo aquela atitude, você fala, nossa, eu não gostei e estou fazendo a mesma coisa. Ou uma atitude que você não tinha pensando e a pessoa teve a sacada rapidamente, porque a gente tem feito quando está, como a gente usa a sala de vídeo, às vezes, a Cidinha está intervindo, a Andréia... No meio da intervenção dela, quando não dá resultado, uma entra na intervenção da outra e aí vê que, poxa, ela deu uma dica que eu não havia pensado e fulano chegou lá. [...] (Professora da primeira série, Ítala).

A gente aprende muito, muito mesmo, porque, assim, você vê de repente numa mesma coisa, por exemplo, a gente está trabalhando com produção de texto ou leitura ou alguma coisa assim, então eu tenho a minha estratégia, o meu jeito de trabalhar. E ai, você, observando o colega, você percebe assim, nossa, eu posso ainda tentar sem... Entendeu? Então de ver essa troca mesmo. Então, às vežes, você se sente até assim, sabe quando a gente faz estágio... (Professora da primeira série, Andréa).

Das considerações apontadas pelas professoras em relação ao GAP, gostaria de resgatar a importância dada à intervenção da colega, à co-responsabilidade pela aprendizagem dos alunos e alunas, à idéia de que todos os alunos podem aprender, à tentativa de aprender outras formas de atingir as crianças, à ampliação dos repertórios de ação, ao conhecimento de outras intervenções, ao conhecimento de outras atitudes, à investigação de outras possibilidades de ação.

Penso que o que perpassa as falas das professoras é a questão da possibilidade de aprender com a colega. O encontro com as colegas no GAP foi uma possibilidade de aprendizagem, um momento formativo para cada uma delas, porque, quando as quatro professoras ficaram juntas no GAP, tiveram a possibilidade de conhecer as colegas de outra forma. Cada uma delas expôs, no GAP, como se comportava na sua sala de aula com seus alunos. A possibilidade de se mostrar e de se expor para a colega mostrou as próprias e singulares formas de ensinar, as estratégias e as intervenções singulares de cada uma, assim como deixou explícitas as atitudes na relação com os alunos. A possibilidade de se mostrar para o outro permitiu que esse outro se formasse, aprendendo com sua colega. 
Penso na frase da professora Andréa, quando falou que se sentia como uma "estagiária" ao estar com as colegas. Retomo essa questão pensando nas perspectivas formativas possibilitadas às professoras ao compartilhar a mesma sala de aula, ao olhar as intervenções das suas colegas professoras, ao olhar o que acontecia quando um aluno, frente a uma proposta de uma professora, não reagia, e as mudanças acontecidas quando a outra professora intervinha. $\mathrm{O}$ fato de as professoras terem a possibilidade de que suas colegas pudessem intervir nas suas práticas de forma imediata foi uma questão levantada pelas professoras como de muita importância para a sua formação, especialmente porque abriu a possibilidade de pensar que, efetivamente, existem outras/os formas/ modos de se vincular com os alunos, com o ensino, com a aprendizagem dos alunos e com o conhecimento.

A partir do trabalho coletivo desenvolvido pelas quatro professoras no GAP, foi possível considerar que esse espaço conjunto permitiu que as suas diferenças aparecessem, seja na relação com os alunos seja nas suas estratégias; mas também ficou evidente que, após esse trabalho, as quatro professoras saíram diferentes do que eram antes de ter participado da constituição e do desenvolvimento desse Grupo de Apoio. Acredito que as professoras saíram diferentes do GAP pelo fato de terem assumido a responsabilidade pela aprendizagem de todos os alunos.

O outro, a colega, apresenta-se como possibilidade de ampliar os conhecimentos, lembrando que esse conhecimento possibilitou, também, que as professoras pudessem "atingir" as crianças que as preocupavam, aquelas crianças que "desestabilizam”, que fogem dos padrões. Resgato as considerações de Nuria Pérez de Lara (2006), que nos leva a refletir sobre os outros, alunos e alunas que estão na escola:

el Otro de la Pedagogía (es decir los otros, las otras) son aquellas alumnas y alumnos, que desde sus modos de estar en el mundo la cuestionan, porque hacen tambalear sus principios con su sola presencia en las aulas.

O trabalho conjunto das professoras no GAP possibilitou-lhes enxergar os alunos com outro "olhar". Como apontam Garcia e Alves (2002), as professoras, inconformadas pelo "fracasso" escolar, assumem uma postura investigativa, ao buscar explicações para poder saber por que alguns de seus alunos e alunas aprendem e outros não, "elas querem compreender por que razões e por que caminhos uns foram e por que razões e quais outros caminhos cada um dos outros tomou". Assim, essa postura/pesquisa é uma possibilidade para que a professora consiga "ver o que antes não via, simplesmente, porque não compreendia” (p. 118). 
O GAP trouxe a possibilidade de olhar as intervenções das próprias colegas. Além disso, as crianças tiveram a possibilidade de vivenciar outras experiências com outras professoras. Importa dizer que os avanços das crianças a partir da participação no Grupo de Apoio, segundo as falas das professoras, foram muito significativos.

\section{A IMPORTÂNICA DO GRUPO E DO TRABAHO COLETIVO NA ESCOLA}

O movimento do GA dá conta da importância colocada por Davini (2001), que considera que os programas de formação e as políticas de educação continuada deveriam priorizar os processos comunicativos, o trabalho coletivo, porque esses espaços mostram-se como uma "estimulación permanente del trabajo en equipo, del fortalecimiento de los lazos cooperativos en la acción profesional y en el aceptar los propios límites en 'mi' explicación que pueden ser iluminados por la explicación del 'otro"' (p. 131).

Davini (2001) enfatiza que o problema das escolas e da docência não é um problema "privado". Muitos docentes têm resistido às dificuldades encontradas nas escolas, assumindo sua responsabilidade dentro das paredes da sala de aula. Mas, segundo a autora, não é potencialmente transformador continuar utilizando esse mecanismo de caráter "privado" em um tema que é "público". Todos sabemos que são os professores que, no cotidiano da escola, constroem a cada dia o currículo, "pero esta ineludible mediación realizada por el docente debería dejar de representar una autonomía virtual para convertirse en una autonomía profesional colectiva y no en los espacios privados de la sala de aula" (p. 75).

Na mesma linha que Davini (2001), Zeichner (2002) e Kramer (2003) também apontam a necessidade de os professores perceberem que seus problemas são comuns e que perpassam as paredes da sala de aula, valorizando a dimensão do trabalho conjunto.

Para Zeichner (2002, p. 40), o isolamento dos professores e a ausência de atenção ao contexto social do ensino no desenvolvimento do professor têm como conseqüência que "os professores passam a ver os problemas como seus próprios sem relação com aqueles dos outros professores ou com a estrutura das escolas e dos sistemas escolares". Segundo Zeichner (2002), o isolamento e a desconsideração do contexto social fazem com que os professores não percebam que seu desenvolvimento profissional guarda estreita relação com a organização da escola. O problema está no fato de os professores, ao não fazerem uma 
análise crítica da escola onde estão, não conseguem estabelecer relações entre a organização e estrutura escolar e as implicações que isso tem para seu desenvolvimento profissional. Quando isso acontece, os professores enxergam que o seu esgotamento ou as situações de estresse são questões relacionadas aos seus próprios fracassos pessoais, sem perceber em que medida o desenvolvimento profissional deles na escola depende das possibilidades que a escola ofereça a cada um para a sua formação.

Kramer (2003) aponta a importância da dimensão coletiva no trabalho das professoras, ao considerar a necessidade de possibilitar um "espaço de linguagem" para que a professora possa falar de sua prática e, no diálogo com suas colegas, perceber que o problema não é só seu, não é individual.

A importância do trabalho em grupo, como lugar privilegiado para a formação de professores, é apontado por Geraldi, Messias e Guerra (2000), quando apresentam o papel do grupo para Zeichner:

o grupo oferece a vantagem de os professores poderem apoiar-se e contribuir para o conhecimento uns dos outros. Além disso, os professores vêem que os seus problemas não são só seus e têm relação com os dos outros professores ou com a estrutura das escolas e os sistemas educacionais (2000, p. 259).

O Grupo de Apoio surgiu a partir das discussões acontecidas no GA. Foi uma necessidade real das professoras a busca de alternativas dentro da escola para que as crianças tivessem um espaço diferente de reforço, no sentido de possibilitar outras relações com outras crianças e com outras professoras. As reflexões, as discussões, os trabalhos e as ações surgidas a partir do Grupo de Reflexão sobre Letramento e Alfabetização dão conta da idéia de Hargreaves (1998), quando o autor diz que as escolas têm que se constituir como lugares de trabalho dinâmicos para os professores, dispondo de tempo e recursos para desenvolver uma tarefa conjunta e condições para produzir mudanças coletivas.

Considero fundamental explicitar que, para que a reflexão por parte do professor e do grupo apareça com força na escola, é preciso garantir certas condições no ambiente de trabalho escolar e destaco a instância da gestão democrática na escola, o que implica, segundo Paro (2002), a participação da comunidade. Quando o autor explicita sua concepção sobre participação, formula que a participação na execução das decisões é importante; mas essa participação é considerada como um meio necessário para o que ele chama de "participação propriamente dita", que implica a partilha do poder e a participação na tomada de decisões (p. 16). Ao fazer o diálogo com esse autor, mostro que, quando as 
professoras definiram a constituição do Grupo de Apoio, de fato, tomaram, na suas mãos, a gestão da escola, definindo ações, assumindo a responsabilidade e o poder de fazer com que o reforço passasse a ter outra significação na escola, participando, assim, da tomada de decisão sobre a aprendizagem daqueles alunos que precisavam de outro acompanhamento na sua aprendizagem. Quero dizer que o GA surgiu dentro de uma escola que favorece e promove a partilha de poder e a possibilidade de participar da tomada de decisões, condições que considero fundamentais para que as professoras tenham assumido o seu lugar e sua própria formação, o que considero ter potencializado a busca por caminhos alternativos para que todos os alunos e as alunas aprendessem.

Para finalizar, gostaria de apontar algumas contribuições e perspectivas que se abrem a partir da experiência narrada neste trabalho, o qual mostrou que a constituição de um grupo de trabalho dentro do espaço escolar foi uma instância que promoveu diferentes processos formativos de todos aqueles que dele participaram. Faço isso pensando na potencialidade de promover a formação de professores no espaço escolar.

O fato de o grupo ter sido constituído na escola favoreceu que as discussões levassem em consideração as condições (da escola e dos professores) em que a educação acontecia. Tendo-as como pano de fundo, foi possível refletir sobre o movimento prática-teoria-prática: partir da prática, buscar elementos e bases teóricas e, posteriormente, retomar a prática com uma nova visão, porque enriquecida pelas reflexões elaboradas dentro do grupo, e não de forma solitária. As discussões teóricas foram importantes para a formação e para a organização do trabalho docente e ganharam outros sentidos porque estiveram em função da prática, e não o inverso. Partir da prática implicou que, no grupo, fossem valorizados e reconhecidos os conhecimentos e as experiências das professoras, mobilizando o processo de reflexão e sistematização dos conhecimentos sobre a própria prática pedagógica.

Resgato a importância de as professoras assumirem um papel ativo na sua formação já que foram elas mesmas que determinaram o percurso do grupo, que se foi delineando a partir das inquietações e problematizações surgidas ali. Assim, as propostas de estudo e todas as ações definidas surgiram a partir das necessidades que as professoras consideravam importantes que fossem resolvidas, discutidas, assumindo, desse modo, sua formação.

Considero que, quando as professoras assumiram sua formação, começaram a fazer propostas em relação a aspectos relacionados não só 
à gestão da sala de aula, mas também apontaram ações relacionadas à gestão da escola, promovendo práticas diferentes das já instituídas. Assim, as professoras reconheceram que tinham um lugar na escola, perceberam que tinham poder de decisão, poder para agir e transformar, participando da gestão escolar. Como aponta Kramer (2003, p. 20), a possibilidade de instituir o novo aparece quando esse novo foi gerado "por perguntas vivas de uma comunidade atuante e reconhecida como tal".

Finalmente, acredito que a experiência no grupo mostrou a importância de considerar a dimensão coletiva na escola, sendo um espaço propício para que a fala das professoras apareça. Penso na força da palavra, no diálogo e na interlocução das professoras como uma instância possível na promoção da autonomia profissional. O exercício da palavra possibilitou a tomada de consciência de seus problemas, a união a partir dos conflitos, a organização de sua própria aprendizagem e a busca conjunta de mudanças. O grupo, ao resgatar a dimensão coletiva do trabalho docente, apontou que as dificuldades não são particulares ou individuais e podem ser compreendidas, se consideradas as contradições postas na escola como um todo. O grupo, em sua dimensão coletiva, mostrou que é possível acolher todas as crianças na escola quando se assume a responsabilidade pela aprendizagem de todos os alunos.

\section{NOTAS}

${ }^{1}$ O presente trabalho foi realizado com o apoio do Conselho Nacional de Desenvolvimento Científico e Tecnológico (CNPq - Brasil). O artigo, em seu conteúdo e sua forma, inspira-se em trabalho publicado na forma de pôster na 29. $2^{2}$. Reunião Anual da ANPED, com o título: "O grupo e a formação na escola: buscando alternativas para a alfabetização".

${ }^{2} \mathrm{Um}$ das formas escolhidas pela SME para estabelecer um diálogo com a comunidade foram os Boletins on-line.

${ }^{3}$ No curso, as professoras recebiam material produzido pelo Programa de Formação de Professores Alfabetizadores, que tem como sustento teórico as pesquisas/estudos desenvolvidos por Ferreiro e Teberosky, numa perspectiva piagetiana.

${ }^{4}$ Smolka (2003) aponta que as pesquisas desenvolvidas por Ferreiro e Teberosky explicitam as funções e a funcionalidade da escrita no processo de alfabetização, numa situação experimental, procurando estabelecer padrões evolutivos enquanto seqüência de níveis, apresentando um modo de organização dos conhecimentos infantis em termos de hipótese pré-silábica, silábica, silábico-alfabética, inferidas pelas respostas das crianças. A crítica da autora é que Ferreiro e Teberosky analisam a relação da criança com a escrita, como objeto de conhecimento, independentemente das condições de interação social e das situações de ensino. Segundo a autora, essas pesquisas têm como pano de fundo concepções que guardam relação com o estruturalismo (lingüístico/Chomsky e construtivista/Piaget, a linguagem é considerada, a priori, com suas propriedades, como objeto a ser conhecido), 
evidenciando que essas elaborações teóricas têm deixado de lado o aspecto sócio-histórico.

${ }^{5}$ FRANÇA, Carlos et al. Ansiedade Infantil - Do âmbito familiar ao escolar. In: AMAE educando, n. 291, p. 28-33, maio 2000.

${ }^{6}$ SERVIDONE, Mabel. Leitor escritor ou observador distanciado. 1993. 129f. Dissertação (Mestrado em Educação), Faculdade de Educação, Universidade Estadual de Campinas, Campinas, 1993.

${ }^{7}$ São Paulo (Estado) Secretaria da Educação. Coordenadoria de estudos e Normas Pedagógicas, Atividades matemáticas: ciclo básico. São Paulo: SE/CENP, 1991, Volumes 1 e 2. Textos sugeridos pela orientadora pedagógica.

${ }^{8}$ Agradeço às professoras terem-me permitido socializar as suas falas.

${ }^{9}$ Nome fictício.

\section{REFERÊNCIAS}

BAKHTIN, M. Estética da criação verbal. São Paulo: Martins Fontes, 2003.

CERTEAU, Michel de. A invenção do cotidiano: artes de fazer. 8 ed. Petrópolis: Vozes, 2002. COLLARES, Cecília Azevedo Lima; MOYSÉS, Maria Aparecida Affonso; GERALDI, João Wanderley. Educação continuada: a política da descontinuidade. Revista Educação \& Sociedade, n. 68, 2001.

DAVINI, Maria Cristina. La formación docente en cuestión: política y pedagogía. Buenos Aires: Paidós, 2001.

DAVINI, Maria Cristina. Formación docente, análisis y perspectivas. Conferencia en el $10^{\circ}$ Congreso de APHU, 9 de octubre de 1999. Disponível em: $<$ http://www.internet.com.uy/aphu/formacion_profes.htm>. Acesso: fevereiro 2004.

ESCOLA PADRE FRANCISCO SILVA. Projeto Político Pedagógico, 2005.

FREIRE, Paulo. Pedagogia da autonomia: saberes necessários à prática educativa. 17 ed. São Paulo: Paz e Terra, 2001.

GARCIA, Regina Leite; ALVES Nilda. Conversa sobe pesquisa. In: ESTEBAN, Maria Teresa e ZACCUR, Edwiges. (Orgs.) Professora-pesquisadora - uma práxis em construção. Rio de Janerio: DP\&A, 2002.

GERALDI, Corinta Maria Grisolia. Escola Viva: política educacional por uma escola contra a barbárie. In: GERALDI, Corinta M. G.; RIOLFI, Cláudia Rosa; GARCIA Maria de Fátima. (Orgs.). Escola Viva: elementos para a construção de uma educação qualidade social. Campinas, SP: Mercado de Letras, 2004.

GERALDI, Corinta Maria Grisolia; MESSIAS, M.; GUERRA; M. Refletindo com Zeichner: Um encontro orientado por preocupações políticas, teóricas e epistemológicas. In: GERALDI, C. M. G.; FIORENTINI, D.; PEREIRA, E. Cartografias do trabalho docente. Professor(a)-Pesquisador(a). Campinas: Mercado das Letras, 2000.

GERALDI, Wanderley. A diferença identifica. A desigualdade deforma. Percursos bakhtinianos de construção ética e estética. In: FREITAS, M. T; JOBIM e SOUZA; S., KRAMER, S. (Orgs.). Ciências humanas e pesquisa: Leituras de Mikhail Bakhtin. São Paulo: Cortez, 2003.

GIMENO SACRISTÁN, José. Profesionalización docente y cambio educativo. Universidad de Valencia, 1988. (Mimeogr.)

GINZBURG, Carlo. Sinais. Raízes de um paradigma indiciário. In: Mitos, emblemas, sinais. São Paulo: Companhia das Letras, 1989. p 143-179. 
HARGREAVES, Andy. Dimensiones subjetivas e institucionales de la formación docente. In: BIRGIN, A. et. al. (Compiladoras). La formación docente. Cultura, escuela e política. Debates y experiencias. Buenos Aires: Troquel Educación, 1998.

KRAMER, Sonia. Por entre as pedras: arma e sonho na escola. 3 ed. ( $3^{\text {a }}$ impressão) São Paulo: Ática, 2003.

MIOTELLO, Valdemir. Apresentação: de objetos a sujeitos - sentidos para os caminhos do humano do homeme. In: ALINE et al. Veredas bakbtinianas - de obejtos a sujeitos. São Carlos: Pedro \& João Editores, 2006.

PARO, Vítor Henrique. Gestão democrática da escola pública. 3 ed. São Paulo: Ática, 2002.

PÉREZ de LARA, Nuria. Escuchar al otro dentro de sí, I parte. Disponíevl em: <http://virtual.flacso.org.ar/mod/book/print.php?id=3910>. Acesso em: junho de 2006.

PREFEITURA MUNICIPAL DE CAMPINAS. Diário Oficial de Campinas. n. 8133, ano XXXIV, 25 fev. 2003.

ROCKWELL, E; EZPELETA, Justa. Etnografia na pesquisa educacional. In: EZPELETA, Justa; ROCKWELL, E. (Org.). Pesquisa participante. São Paulo: Cortez: Autores Associados, 1986.

SECRETARIA MUNICIPAL DE EDUCAÇÃO DE CAMPINAS. Boletins SME, Campinas, n.1, fev./out. 2001a. Disponível em: http://www.campinas.sp.gov.br/ smenet/boletins/boletim_01.htm>. Acesso em: 15 dez. 2001a.

SECRETARIA MUNICIPAL DE EDUCAÇÃO DE CAMPINAS. Boletins SME, Campinas, n. 3, fev./out. 2001b. Disponível em:

<http://www.campinas.sp.gov.br/smenet/boletins/boletim_03.htm>. Acesso em: 15 dez. 2001b. SECRETARIA MUNICIPAL DE EDUCAÇÃO DE CAMPINAS. Educação Municipal investe em formação para reduzir repetência. Notícias da educação, 04 fev. 2004. Disponível em: <http://www.campinas.sp.gov.br/smenet/noticias/noticia_2004_02_04b.htm>. Acesso em: 10 mar. 2004.

SMOLKA, Ana Luiza. A criança na fase inicial da escrita: alfabetização como processo discursivo. 11 ed. São Paulo: Cortez; Campinas, SP: UNICAMP, 2003. (Coleção Passando a limpo).

ZEICHNER, K. M. Para além da divisão entre professor-pesquisador e pesquisador acadêmico. In: GERALDI, C. M. G.; FIORENTINI, D.; PEREIRA, E. (Orgs). Cartografias do trabalho docente. Professor(a)-Pesquisador(a). Campinas: Mercado das Letras, 2000.

ZEICHNER, K.M. Formando professores reflexivos para uma educação centrada no aprendiz: possibilidades contradições. In: ESTEBAN, Maria Teresa; ZACCUR, Edwiges (Orgs.) Professora-pesquisadora - uma práxis em construção. Rio de Janeiro: DP\&A, 2002.

Recebido: $01 / 04 / 08$

Aprovado: $16 / 12 / 08$

Contato:

Rua Domingos Cerone, 267

Jd. Sta. Genebra II

Campinas - SP

13084-789 